\title{
BMJ Open Hypertension prevalence alteration in 92815 nurses based on the new standard by 2017 ACC/AHA hypertension guideline: observational cross-sectional study from China
}

Bin Zhao, ${ }^{1}$ Jing Li, ${ }^{1}$ Jie Liu, ${ }^{1}$ Yuming Hao, ${ }^{2}$ Yanjie Zhen, ${ }^{2}$ Di Feng, ${ }_{7}^{1}$ Menghui Xu, ${ }^{1}$ Ximin Chen, ${ }^{3}$ Xiulan Yang, ${ }^{4}$ Aifang Zuo, ${ }^{5}$ Rufu Jia, ${ }^{6}$ Ruiqin Zhang, ${ }^{7}$ Ailing Fan, ${ }^{8}$ Yun Wang, ${ }^{9}$ Meijin Yuan, ${ }^{10}$ Li Tong, ${ }^{11}$ Shuling Chen, ${ }^{12}$ Jing Cui, ${ }^{13}$ Meizhu Zhao, ${ }^{14}$ Wei Cui ${ }^{2}$

To cite: Zhao B, Li J, Liu J, et al. Hypertension prevalence alteration in 92 815 nurses based on the new standard by 2017 ACC/ AHA hypertension guideline: observational cross-sectional study from China. BMJ Open 2019;9:e027201. doi:10.1136/ bmjopen-2018-027201

- Prepublication history for this paper is available online. To view these files, please visit the journal online (http://dx.doi. org/10.1136/bmjopen-2018027201).

Received 26 0ctober 2018 Revised 17 July 2019 Accepted 24 July 2019
Check for updates

(C) Author(s) (or their employer(s)) 2019. Re-use permitted under CC BY-NC. No commercial re-use. See rights and permissions. Published by BMJ.

For numbered affiliations see end of article.

Correspondence to

Professor Wei Cui;

cuiwei21c@163.com

\section{ABSTRACT}

Objectives This study aimed to elucidate the status of hypertension and to analyse the hypertension changes in prevalence, awareness, treatment and control rate among the portion of Chinese nursing staff based on the 2017 American College of Cardiology (ACC)/American Heart Association (AHA) High Blood Pressure Guideline and the 2010 Chinese Guideline for the Management of Hypertension.

Design Cross-sectional study.

Setting 512 medical institutions in 13 cities in Hebei Province.

Participants The candidates of registered nurses from 512 medical institutions in 13 cities in Hebei Province $(\mathrm{N}=143772$ ) were invited to participate in the survey, and few of them who refused to participate were excluded from the research group based on the reasons that 93603 incumbent nurses at the age of 18-65 accepted to the survey and submitted questionnaires online. Undoubtedly, a response rate of $65.11 \%$ was achieved. After excluding 788 individuals with incomplete information in the questionnaires, 92815 participants were included in the final analysis.

Main outcome measures The prevalence, awareness, treatment and control rates of hypertension.

Results 92815 participants were included in the final analysis, among which consisted of 3677 men (3.96\%) and 89138 women $(96.04 \%)$. The mean age of the participants was $31.65(\mathrm{SD}=7.47)$ years.

We demonstrated that 26875 nursing staff were diagnosed as having hypertension according to the new standard by the 2017 ACC/AHA guideline, more than 20551 cases compared with the previous threshold on the 2010 Chinese guideline. The prevalence of hypertension among nursing staff was $28.96 \%$ in the context of the 2017 ACC/AHA guideline, 3.25 times higher than that $(6.81 \%)$ evaluated by the criteria of the 2010 Chinese guideline. However, the awareness, treatment and control rate $(13.50 \%, 10.73 \%$ and $0.81 \%$ ) were $3.25,3.22$ and 17.48 times lower than those $(57.37 \%, 45.30 \%$ and $14.97 \%)$ based on the 2010 Chinese guideline, respectively.

\section{Strengths and limitations of this study}

- This study described the current status of the hypertension in nurses according to the 2010 Chinese guideline and the 2017 American College of Cardiology/American Heart Association guideline.

- This study had a large sample size, covering 13 regions, and described the prevalence and distribution of hypertension in different population groups.

- Not all the relationships between hypertension and specific factors identified in this study were investigated.

Conclusions This research illustrated that it was crucial to improve the awareness rate, drug treatment rate and control rate of hypertension for nurses. Meanwhile, according to the 2017 ACC/AHA guideline, the prevalence of hypertension in China will increase significantly, which poses a more severe challenge to the management of hypertension in China.

\section{INTRODUCTION}

With the rapid development of society and economy, changes in lifestyle and the ageing of the population, hypertension has become one of the most important public health issues in the world. Its complications are associated with high morbidity and mortality, as well as high rate of consumption of medical resources. ${ }^{1}$ The direct economic burden caused by hypertension in China in 2013 amounted to 210.3 billion yuan, accounting for $6.61 \%$ of the total expenditure on health in China. ${ }^{2-4}$ According to the China Health and Nutrition Survey (CHNS) data from 1991 to 2011, the adjusted prevalence rate of hypertension in Chinese over 18 years old increased from $15.6 \%$ to $20.9 \%$, and the 
prevalence rate of hypertension increased ${ }^{5}$; however, the awareness, treatment and control rates were still low. ${ }^{6}$

The 2017 American Heart Association (AHA)/American College of Cardiology (ACC) guideline for the prevention, detection, evaluation and management of high blood pressure (BP) in adults has been recently released. A significant transformation in the guideline is the shift in the definition of hypertension, from a systolic blood pressure (SBP) of $\geq 140 \mathrm{~mm} \mathrm{Hg}$ or a diastolic blood pressure (DBP) of $\geq 90 \mathrm{~mm} \mathrm{Hg}$ to an SBP of $\geq 130 \mathrm{~mm} \mathrm{Hg}$ or a DBP of $\geq 80 \mathrm{~mm} \mathrm{Hg}$. According to the 2017 AHA/ ACC guideline, the prevalence rate of hypertension increased from $31.9 \%$ to $45.6 \%$ in the USA. ${ }^{7}$

The 2017 ACC/AHA guideline may bring critical effects on the hypertension status in different regions worldwide. $^{8-11}$ Recently, more and more researchers focused on the issues about the potential impacts of the updated guideline on the Chinese population. A nationally representative cross-sectional study examined the hypertension prevalence rate according to the new guideline and found an absolute increase of $17.0 \%$ among adults aged 45-75 years in China. ${ }^{12}$ Additionally, a survey examined the effects of the new guideline in Southwest China and found that the prevalence of hypertension was nearly twice than that in the Chinese hypertension guideline. ${ }^{13}$ Findings from previous studies were mainly focused on the increase in the prevalence of hypertension in the Chinese general population under the new guideline, but it was still largely unclear how the new guideline exerted influence on the hypertension status in different social communities in China. Moreover, the BP levels of nursing staff, a special class of professional group whose work was of high intensity, characterised by high stress level and requiring frequent rotating shifts, should be paid more attention to. ${ }^{14} 15$ This study is a cross-sectional survey based on a large number of nursing staffs. The purpose was to analyse the alteration of prevalence, awareness, treatment and control rates of hypertension in Chinese nursing staff based on the 2017 ACC/AHA guideline and the 2010 Chinese guideline, as well as the characteristics of the newly diagnosed hypertension population.

\section{METHODS}

\section{Participants and data collection}

This cross-sectional study was conducted from October 2016 to February 2017 using a general survey design. Candidates of registered nurses from 512 medical institutions in 13 cities in Hebei Province $(\mathrm{N}=143772)$ were invited to participate in the survey, and few of them who refused to participate were excluded from the research group. Based on who accepted the survey and submitted questionnaires online, we collected 93603 incumbent nurses aged 18-65 years. Undoubtedly, a response rate of $65.11 \%$ was achieved. After excluding 788 individuals with incomplete information in the questionnaires, 92815 participants were included in the final analysis.
Electronic folders were distributed to the Nursing Quality Control Center (NQCC) of each city through the NQCC of Hebei Province. The folder contained three documents: the link to the electronic questionnaire (SO JUMP), a document on BP measurement precautions and an investigation notice. On receiving the folder, the contact person of each NQCC sent it to the nursing department of all medical institutions in the different cities. Then, the nursing department sent it to the head managers of the departments, who organised the nurses to fill in the questionnaire online. A researcher was arranged to report the response rate to the NQCC of each city every day. The questionnaire content mainly involved (1) the demographic characteristic: hospital name, hospital grade, department, name, age, gender, height and weight; (2) the SBP and the DBP; and (3) the risk factors associated with hypertension: monthly night shift frequency, years of hyperlipidaemia, years of diabetes, years of hypertension, educational status, marital status, menstruation condition, reproductive history, history of abortion, whether the participant received hormone replacement therapy, smoking habit, alcohol drinking, physical exercise and family history of hypertension. ${ }^{16-19}$

\section{Participants and public involvement}

In this study, self-report was adopted, and all the participants were nurses who understood the effect of BP measurement by themselves. After receiving the notification on the BP survey, all participants filled in and submitted relevant data online, and those who did not accept could refuse to participate. Although the participants or the public were not formally involved in the design and conduct of the study, the questionnaire used for data collection and the specific assessment conduction were developed based on previous experiences in other surveys and expert opinions. The research data was sent to the Municipal Nursing Quality and Control Centre in Hebei Province.

\section{Measurement}

BP measurement and data reporting

The nursing staff measured BP by themselves and reported data through the network. Although nurses mastered the BP measurement method generally, the researchers standardised the method of BP measurement and gave relevant attention in order to reduce measurement bias as much as possible. In order to ensure the accuracy of the report and BP data, a series of measures were adopted for quality control. First, our research group established a three-level supervision mechanism that contained the NQCC, nursing departments and head nurses of hospitals at all levels. Each day during the investigations, research group members exported data from the information platform to conduct data analysis, calculated the number of staff who had finished the questionnaire in each hospital, then fed it back it to their municipal quality control centres for controlling researching progress. Additionally, each questionnaire was checked and 
verified by professional quality investigators. After that, the results of verified data were sent to the municipal quality control centres for complementing the missing items and correcting mistakes. What is more, we also attached important cautions while releasing announcement of taking BP measurements.

\section{BP measurements}

Choose a regular calibration of the mercury sphygmomanometer or validated electronic sphygmomanometer. Use the standard specification cuff with air bag, which is $22 \mathrm{~cm}$ in length and $12 \mathrm{~cm}$ in width. Obese individuals or individuals with large arm circumferences used a large sized balloon cuff, and the upper arm was wrapped up at least $80 \%$ by the air bag. Each participant was asked to take a rest at least for $5 \mathrm{~min}$; any vigorous activity was avoided; cigarettes and beverages containing caffeine, such as tea and coffee, were forbidden within $30 \mathrm{~min}$; and the participants were instructed to empty their bladder before the BP measurement. BP was measured in a sitting position; the right upper arm should be exposed and the cuff should be kept at the same level as the heart. Each participant was measured three times with an interval time of $1 \mathrm{~min}$, and the average of the last two readings was used for analysis.

\section{Definitions}

Hypertension was defined as an SBP of $\geq 140 \mathrm{~mm} \mathrm{Hg}$ or a DBP of $\geq 90 \mathrm{~mm} \mathrm{Hg}$, and/or a self-report of having an existing diagnosis of hypertension in accordance with the 2010 Chinese guideline. The new classification designates $\mathrm{SBP} \geq 130 \mathrm{~mm} \mathrm{Hg}$ or DBP $\geq 80 \mathrm{~mm} \mathrm{Hg}$ and/or self-report of having an existing diagnosis of hypertension as hypertension according to the 2017 ACC/AHA guideline.

The ratio of hypertension to the total population was the prevalence of hypertension. Awareness of hypertension was defined as any self-reported previous diagnosis of hypertension by a healthcare professional physician; treatment was self-reported use of a prescription medication for hypertension management within the 2 weeks at the time of the interview; control referred to pharmacological treatment of hypertension associated with $\mathrm{SBP}<140 \mathrm{~mm} \mathrm{Hg}$ and $\mathrm{DBP}<90 \mathrm{~mm} \mathrm{Hg}$ during the past 2 weeks.

In addition, the study also estimated the prevalence ( $\mathrm{SBP} \geq 130 \mathrm{~mm} \mathrm{Hg}$ or $\mathrm{DBP} \geq 80 \mathrm{~mm} \mathrm{Hg}$ ) and control rate ( $\mathrm{SBP}<130 \mathrm{~mm} \mathrm{Hg}$ and $\mathrm{DBP}<80 \mathrm{~mm} \mathrm{Hg}$ ) of hypertension according to the 2017 ACC/AHA guideline.

Response rate was defined as the number of nurses responding to the questionnaire online divided by the total number of registered nurses in Hebei Province.

\section{Statistical analysis}

All variables were statistically described, the normality of the continuous variables was assessed, variables with a normal distribution were presented as mean $\pm \mathrm{SD}$, variables with a skewed distribution were reported with medians and IQRs, and categorical data were presented by the percentage description. The prevalence of hypertension, as well as awareness, treatment and control rates of hypertension among hypertensive participants, was calculated according to the two guidelines. In addition, we reported the prevalence for each of the background characteristics of the study. Then we calculated the distribution of the population across five groups, including those who did not have an existing diagnosis of hypertension with $\mathrm{SBP} / \mathrm{DBP}<120 /<80 \mathrm{~mm} \mathrm{Hg}, 120-129 /<80 \mathrm{~mm}$ $\mathrm{Hg}, 130-139 / 80-89 \mathrm{~mm} \mathrm{Hg}$ and $\geq 140 / 90 \mathrm{~mm} \mathrm{Hg}$, and those who had an existing diagnosis of hypertension. To investigate the factors associated with newly diagnosed hypertension, the possible risk factors (gender, age, body mass index (BMI), years of hyperlipidaemia, years of diabetes, smoking, alcohol drinking and family history of hypertension) were incorporated into a multiple logistic regression analysis. Analyses were performed by using SPSS V.21.0 software. A two-sided $p$ value of $<0.05$ was considered statistically significant.

\section{RESULTS}

\section{Demographic characteristics}

A total of 93603 participants from 512 medical institutions in 13 cities were enrolled in this study, accounting for $65.11 \%$ of the total number of registered nurses in Hebei Province. The main reason for non-response might be that some invited nurses had retired but had not logged out of the registration system; being on leave, including maternity leave, study leave and other reasons during the period of data collection; or refusing to participate.

After excluding 788 individuals with incomplete questionnaires, information in the 92815 participants was included in the final analysis, among which consisted of 3677 men (3.96\%) and 89138 women (96.04\%). The median age of participants was 30 (IQR 26-35) years (age range: $18-65$ years). Our sample contained more people aged 35 years and younger $(76.59 \%$, table 1$)$. Hypertension levels in different groups are shown in table 1 . With increases in BMI, years of diabetes and years of hyperlipidaemia, the $\mathrm{BP}$ presented an increasing trend.

Prevalence, awareness, treatment and control rate of hypertension in Chinese nurses according to the two editions of the guidelines

According to the 2017 ACC/AHA guideline, the prevalence of hypertension increased from $6.81 \%$ to $28.96 \%$, and the prevalence rate was 3.25 times higher than that defined in the 2010 Chinese guideline. The awareness rate, drug treatment rate and control rate of hypertension according to the two guidelines are shown in table 2.

Multidimensional comparative analysis of hypertension prevalence among nursing staff

According to the 2017 ACC/AHA guideline, the number of people with high BP in nursing staff rose from 6324 to 26875 , with a total increase of 20551. The times of increase of hypertension prevalence in different groups according to the new guideline are shown in table 3 . 
Open access

Table 1 Characteristics of study participants $(\mathrm{N}=92815)$

\begin{tabular}{|c|c|c|c|c|}
\hline Variable & $\mathbf{N}$ & $\begin{array}{l}\text { Percentage } \\
(\%)\end{array}$ & $\begin{array}{l}\text { SBP } \\
\text { Median (IQR)/mean } \pm \text { SD }\end{array}$ & $\begin{array}{l}\text { DBP } \\
\text { Median (IQR) }\end{array}$ \\
\hline Overall & 92815 & 100 & $110(102-120)$ & $70(64-80)$ \\
\hline Female & 89138 & 96.04 & $110(101-120)$ & $70(63-80)$ \\
\hline Male & 3677 & 3.96 & $123(120-130)$ & $80(75-85)$ \\
\hline $26-35$ & 53799 & 57.96 & $110(100-120)$ & $70(62-78)$ \\
\hline $36-45$ & 14989 & 16.15 & $110(105-120)$ & $70(65-80)$ \\
\hline $46-55$ & 6376 & 6.87 & $120(110-130)$ & $80(70-85)$ \\
\hline $56-65$ & 250 & 0.27 & $130(120-135)$ & $80(75-86)$ \\
\hline Normal & 57077 & 61.50 & $110(100-120)$ & $70(61-77)$ \\
\hline Overweight & 22235 & 23.96 & $118(110-123)$ & $72(70-80)$ \\
\hline Obese & 6253 & 6.74 & $120(110-130)$ & $79(70-80)$ \\
\hline Missing data & 213 & 0.23 & - & - \\
\hline \multicolumn{5}{|l|}{ Years of hyperlipidaemia* } \\
\hline 0 & 86900 & 93.63 & $110(101-120)$ & $70(63-80)$ \\
\hline$\sim 5$ & 4837 & 5.21 & $120(110-130)$ & $80(70-85)$ \\
\hline$\sim 10$ & 636 & 0.69 & $125(110-140)$ & $80(70-90)$ \\
\hline$>10$ & 56 & 0.06 & $130 \pm 18$ & $80(75-90)$ \\
\hline Missing data & 84 & 0.09 & - & - \\
\hline \multicolumn{5}{|l|}{ Smoking } \\
\hline Never & 91020 & 98.07 & $110(102-120)$ & $70(64-80)$ \\
\hline$<10$ cigarettes/day & 1280 & 1.38 & $110(105-120)$ & $70(66-80)$ \\
\hline 10-20 cigarettes/day & 419 & 0.45 & $110(105-120)$ & $70(68-80)$ \\
\hline >20 cigarettes/day & 96 & 0.10 & 110 (103-120) & $70(70-80)$ \\
\hline \multicolumn{5}{|l|}{ Alcohol drinking } \\
\hline Never & 45984 & 49.54 & 110 (102-120) & $70(64-80)$ \\
\hline Occasionally & 46263 & 49.84 & $110(102-120)$ & $70(64-80)$ \\
\hline Often & 568 & 0.61 & $110(102-120)$ & $70(69-80)$ \\
\hline \multicolumn{5}{|c|}{ Family history of hypertension } \\
\hline Yes & 44451 & 47.89 & $110(102-120)$ & $70(64-80)$ \\
\hline No & 48364 & 52.11 & $110(102-120)$ & $70(64-80)$ \\
\hline
\end{tabular}

*With the missing data.

†BMI was used to classify participants into categories of underweight $(<18.5)$, normal weight $(18.5$ to $<24)$, overweight $(24$ to $<28)$ and obese ( $\geq 28)$.

BMI, body mass index; DBP, diastolic blood pressure; SBP, systolic blood pressure. 


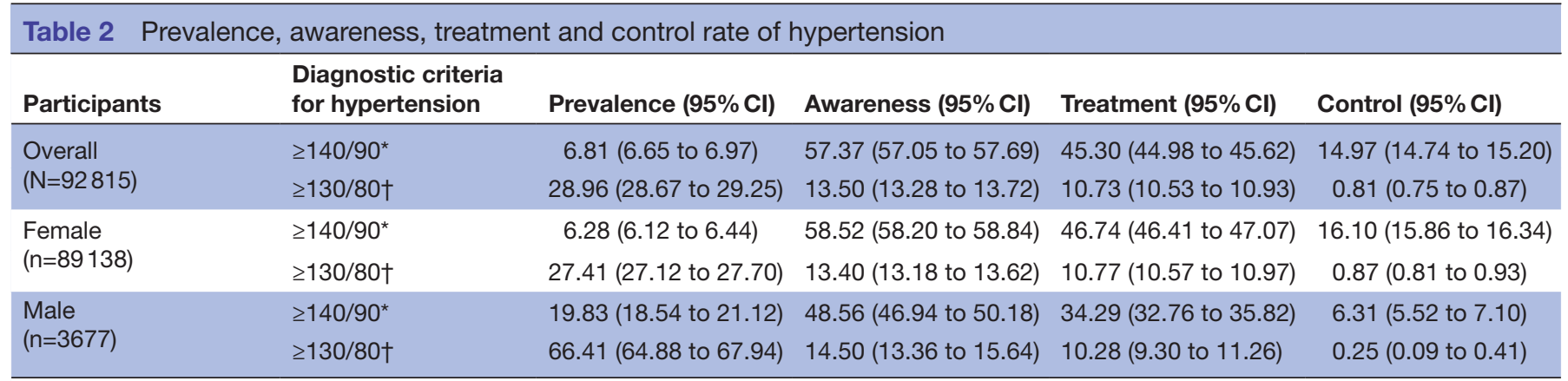

${ }^{*}$ According to the diagnostic criteria for hypertension in the 2010 Chinese guideline.

†According to the diagnostic criteria for hypertension in the 2017 edition of the guideline.

Table 4 shows that $60.68 \%, 10.36 \%, 22.14 \%$ and $2.90 \%$ of nurses not having an existing diagnosis of hypertension had SBP/DBP levels of $<120 / 80 \mathrm{~mm} \mathrm{Hg}, 120-129 /<80 \mathrm{~mm}$ $\mathrm{Hg}, 130-139 / 80-89 \mathrm{~mm} \mathrm{Hg}$ and $\geq 140 / 90 \mathrm{~mm} \mathrm{Hg}$, respectively. Additionally, $3.91 \%$ of the nurses had an existing diagnosis of hypertension. Among the nurses who did not have an existing diagnosis of hypertension, nurses with higher BP were older and were more likely to be men, overweight or obese, and tended to have hyperlipidaemia for less than 10 years or diabetes for less than 5 years.

Table 5 shows that gender (OR $0.647,95 \%$ CI 0.585 to $0.716, \mathrm{p}<0.001$ ), age (OR $0.538,95 \%$ CI 0.520 to $0.557, \mathrm{p}<0.001$ ), BMI (OR $0.760,95 \%$ CI 0.729 to 0.791 , $\mathrm{p}<0.001$ ), years of hyperlipidaemia (OR $0.426,95 \%$ CI 0.397 to $0.458, \mathrm{p}<0.001$ ) and years of diabetes (OR 0.597 , $95 \%$ CI 0.517 to $0.690, p<0.001$ ) were factors significantly associated with newly diagnosed hypertension. Women were more likely to be newly diagnosed with hypertension than men according to the 2017 ACC/AHA guideline. Besides, participants with no hyperlipidaemia, no diabetes, with lower age and with lower BMI value were more likely to be newly diagnosed with hypertension.

\section{DISCUSSION}

At present, there were few studies on the current status of hypertension among nurses. This study was a cross-sectional survey based on a large sample of nursing staff. The final analysis included 92815 participants from 512 medical institutions in 13 cities in Hebei Province. According to the 2010 Chinese guideline, the prevalence rate of hypertension was $6.81 \%$ in this study. $\mathrm{Li}$ et $a l^{20}$ investigated 4032 cardiovascular physicians from 386 hospitals in China and found that the prevalence of hypertension among them was $13.1 \%$. Liu $e t a l^{21}$ analysed the prevalence of hypertension among 1369 medical staff in a tertiary academic hospital in Zhengzhou, and the prevalence of hypertension was $18.33 \%$. The prevalence of hypertension in this survey was lower than the above results, which may be related to the lower age and the greater proportion of women in the nursing staff. The report of China Health and Family Planning Commission indicated that the awareness rate of hypertension among people over 18 years old in China was $46.5 \%$, the drug treatment rate was $41.1 \%$, and the control rate was $13.8 \%$ in 2012. ${ }^{22}$ In addition, a survey ${ }^{23}$ of 174621 people aged 18 years or older in 31 provinces in China from 2013 to 2014 showed that the awareness, treatment and control rate were $31.9 \%, 26.4 \%$ and $9.7 \%$, respectively. Lu $e$ e $a l^{24}$ organised a population-based screening hypertension project enrolling around 1.7 million adults aged 35-75 years from all 31 provinces in Mainland China. The rates of hypertension prevalence, awareness, treatment and control were $37.2 \%, 36.0 \%, 22.9 \%$ and $5.7 \%$, respectively. In this survey, the awareness rate of hypertension in nursing staff was $57.37 \%$, the rate of treatment was $45.30 \%$, and the control rate was $14.97 \%$, which were all higher than the above results. However, the control rate of hypertension among female nurses was $16.10 \%$, and that among male nursing staff was only $6.31 \%$. For medical workers, the awareness rate and the drug treatment rate of hypertension should have been higher. There is still a large space for improvement in the awareness rate of hypertension.

In this study, we sought to assess the potential impact of the new hypertension guideline on the status of BP in clinical nurses. According to the 2017 ACC/AHA guideline, the hypertension prevalence rate of nursing personnel in the survey increased to $28.96 \%$, which increased 4.15 times among nurses aged under 45 years and 1.04 times among nurses aged 45 years or older. The prevalence rate of the population with no hyperlipidaemia, no diabetes, with lower age and with lower BMI value increased, suggesting that a more low-risk population would be diagnosed with hypertension. Meanwhile, the awareness rate, drug treatment rate and control rate of hypertension among Chinese nurses decreased from 57.37\%, $45.30 \%$ and $14.97 \%$ to $13.50 \%, 10.73 \%$ and $0.81 \%$, respectively.

A study from South Korea showed that the prevalence of hypertension was $49.2 \%$ based on the 2017 ACC/ AHA guideline, while the number was $30.4 \%$ based on the previous guideline; the control rate decreased from $59.5 \%$ to $16.1 \% .{ }^{25}$ Additionally, a study from Nepal found that if the ACC/AHA guideline was applied, the overall prevalence of hypertension in Nepal would be approximately double (from $21.2 \%$ to $44.2 \%$ ). ${ }^{26}$ According to the standards of the new guideline, the prevalence rate of 
Table 3 Comparison of hypertension prevalence among nursing staff

\begin{tabular}{|c|c|c|c|c|c|c|}
\hline Variable & $\mathbf{N}$ & \multicolumn{2}{|l|}{$\geq 140 / 90^{*}$} & \multicolumn{2}{|l|}{$\geq 130 / 80 \dagger$} & $\begin{array}{l}\text { Times of } \\
\text { increase }\end{array}$ \\
\hline \multicolumn{7}{|l|}{ Gender } \\
\hline Female & 89138 & 5595 & $6.28(6.12$ to 6.44$)$ & 24433 & 27.41 (27.12 to 27.70$)$ & 3.36 \\
\hline Male & 3677 & 729 & 19.83 (18.54 to 21.12$)$ & 2442 & 66.41 (64.88 to 67.94$)$ & 2.35 \\
\hline \multicolumn{7}{|l|}{ Age (years)‡ } \\
\hline $26-35$ & 53799 & 2263 & 4.21 (4.04 to 4.38$)$ & 13532 & 25.15 (24.78 to 25.52$)$ & 4.97 \\
\hline $36-45$ & 14989 & 1784 & 11.90 (11.38 to 12.42$)$ & 5284 & 35.25 (34.49 to 36.01$)$ & 1.96 \\
\hline $46-55$ & 6376 & 1726 & 27.07 (25.98 to 28.16$)$ & 3524 & 55.27 (54.05 to 56.49$)$ & 1.04 \\
\hline $56-65$ & 250 & 91 & 36.40 (30.44 to 42.36$)$ & 185 & 74.00 (68.56 to 79.44$)$ & 1.03 \\
\hline \multicolumn{7}{|l|}{ BMI $\left(\mathrm{kg} / \mathrm{m}^{2}\right) \S \ddagger$} \\
\hline Obese & 6253 & 1120 & 17.91 (16.96 to 18.86$)$ & 3280 & 52.45 (51.21 to 53.69$)$ & 1.93 \\
\hline \multicolumn{7}{|l|}{ Years of hyperlipidaemiał } \\
\hline 0 & 86900 & 4473 & 5.15 (5.00 to 5.30$)$ & 23495 & 27.04 (26.74 to 27.34$)$ & 4.25 \\
\hline$\sim 5$ & 4837 & 1431 & 29.58 (28.29 to 30.87$)$ & 2712 & 56.07 (54.67 to 57.47$)$ & 0.90 \\
\hline$\sim 10$ & 636 & 292 & 45.91 (42.04 to 49.78 ) & 417 & 65.57 (61.88 to 69.26$)$ & 0.43 \\
\hline$>10$ & 127 & 61 & 48.03 (39.34 to 56.72 ) & 95 & 74.80 (67.25 to 82.35$)$ & 0.56 \\
\hline \multicolumn{7}{|l|}{ Years of diabetes $\ddagger$} \\
\hline 0 & 91886 & 5951 & 6.48 (6.32 to 6.64$)$ & 26285 & 28.61 (28.32 to 28.90$)$ & 3.42 \\
\hline$\sim 5$ & 625 & 270 & 43.20 (39.32 to 47.08$)$ & 413 & 66.08 (62.37 to 69.79$)$ & 0.53 \\
\hline$>20$ cigarettes/day & 96 & 5 & 5.21 (0.76 to 9.66$)$ & 31 & 32.29 (22.94 to 41.64$)$ & 5.20 \\
\hline \multicolumn{7}{|l|}{ Alcohol drinking } \\
\hline Never & 45984 & 3085 & 6.71 (6.48 to 6.94$)$ & 13226 & 28.76 (28.35 to 29.17$)$ & 3.29 \\
\hline Occasionally & 46263 & 3194 & 6.90 (6.67 to 7.13$)$ & 13463 & 29.10 (28.69 to 29.51$)$ & 3.22 \\
\hline Often & 568 & 45 & 7.92 (5.70 to 10.14$)$ & 186 & 32.75 (28.89 to 36.61$)$ & 3.14 \\
\hline \multicolumn{7}{|l|}{$\begin{array}{l}\text { Family history of } \\
\text { hypertension }\end{array}$} \\
\hline Yes & 44451 & 2967 & 6.67 (6.44 to 6.90$)$ & 12743 & 28.67 (28.25 to 29.09 ) & 3.30 \\
\hline No & 48364 & 3357 & 6.94 (6.71 to 7.17$)$ & 14132 & 29.22 (28.81 to 29.63$)$ & 3.21 \\
\hline
\end{tabular}

*According to the diagnostic criteria for hypertension in 2010 Chinese guideline.

†According to the diagnostic criteria for hypertension in the 2017 edition of the guideline.

$\ddagger$ With the missing data.

§Body mass index was classified into underweight $(<18.5)$, normal weight $(18.5$ to $<24)$, overweight $(24$ to $<28)$ and obese $(\geq 28)$.

hypertension among nurses in China was lower than that of the above two studies, which might be related to the fact that most of the nurses were female, were lower in age level, and had more medical knowledge and resources. In addition, the difference could be due to several factors, including Nepal's predominantly rural population and low income. However, it is worth noting that the hypertension control rate among nurses according to the new standard is very low, only $0.81 \%$. It had been reported that treatment of hypertension could reduce the risk of stroke and myocardial infarction by $30 \%-43 \%$ and $15 \%$, respectively, along with reducing the risk of a number of 
Table 4 Characteristics of study participants by blood pressure levels ( $\mathrm{N}=92815$ )

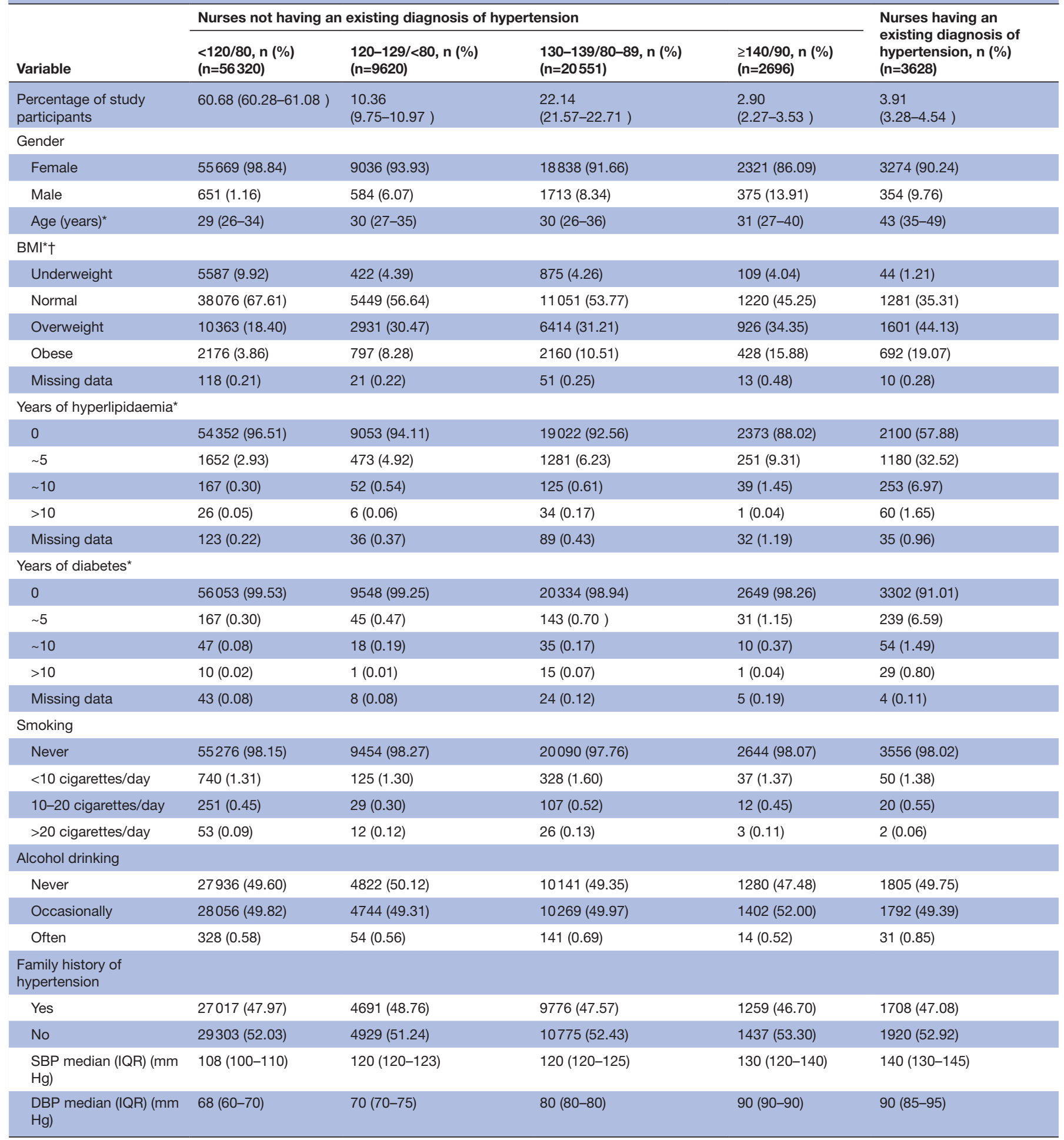

Participants were grouped into the higher category of SBP and DBP. For example, if a person had an SBP of $142 \mathrm{~mm} \mathrm{Hg}$ and a DBP of $88 \mathrm{~mm} \mathrm{Hg}$, she/he was grouped into the $\geq 140 / 90 \mathrm{~mm}$ Hg category.

*With the missing data.

†BMI was used to classify participants into categories of underweight $(<18.5)$, normal weight $(18.5$ to $<24)$, overweight $(24$ to $<28)$ and obese $(\geq 28)$.

$\mathrm{BMI}$, body mass index; DBP, diastolic blood pressure; SBP, systolic blood pressure.

other chronic conditions. ${ }^{27-29}$ Consequently, the nursing staff should pay more attention to the management of BP. Improving lifestyle and monitoring the BP regularly were suggested to control the $\mathrm{BP}$ in a reasonable range.
According to the 2017 ACC/AHA guideline, for patients with clinical cardiovascular disease (CVD), antihypertensive medications should be used if the average $\mathrm{SBP}$ is $\geq 130 \mathrm{~mm} \mathrm{Hg}$ or the average DBP is $\geq 80 \mathrm{~mm} \mathrm{Hg}$. 
Table 5 Multiple logistic regression of factors associated with newly diagnosed hypertension

\begin{tabular}{|c|c|c|c|}
\hline Variables & OR & $95 \% \mathrm{CI}$ & $P$ value \\
\hline Gender & 0.647 & 0.585 to 0.716 & $<0.001$ \\
\hline Age (years) & 0.538 & 0.520 to 0.557 & $<0.001$ \\
\hline BMI $\left(\mathrm{kg} / \mathrm{m}^{2}\right)$ & 0.760 & 0.729 to 0.791 & $<0.001$ \\
\hline $\begin{array}{l}\text { Years of } \\
\text { hyperlipidaemia }\end{array}$ & 0.426 & 0.397 to 0.458 & $<0.001$ \\
\hline Years of diabetes & 0.597 & 0.517 to 0.690 & $<0.001$ \\
\hline Smoking & 1.070 & 0.921 to 1.243 & 0.379 \\
\hline Alcohol drinking & 0.962 & 0.906 to 1.022 & 0.210 \\
\hline $\begin{array}{l}\text { Family history of } \\
\text { hypertension }\end{array}$ & 0.946 & 0.890 to 1.006 & 0.077 \\
\hline
\end{tabular}

BMI, body mass index.

For adults without CVD who have a 10-year predictive risk factor for atherosclerotic CVD of $\geq 10 \%$, antihypertensive medications should be used if the average SBP is $\geq 130 \mathrm{~mm} \mathrm{Hg}$ or the average DBP is $\geq 80 \mathrm{~mm} \mathrm{Hg}$. ${ }^{7}$ Despite the fact that the number of nursing staff who need the medication treatment is speculated to increase according to the new guideline, they should take both their own conditions and medical history into consideration to make a reasonable judgement on whether it is necessary and proper for them to take the medicine.

Meanwhile, the ACC/AHA guideline would require expansion of the necessary public health infrastructure to manage the substantial increase in the public health burden of hypertension in China. Different countries have different epidemiological characteristics, genetic background, disease control and economic levels. More facts founded on evidence-based medicine are needed to confirm whether the new guideline is applicable to China, how to determine the boundary value of hypertension and whether lowering the hypertension diagnosis standard to $130 / 80 \mathrm{~mm} \mathrm{Hg}$ can improve the prognosis. The number of patients with hypertension in China is huge, and the medical resources are relatively insufficient. The report of the Chinese Center for Disease Control and Prevention in 2013 pointed out that the number of hypertension in China had risen to 330 million in 2010, and the direct economic burden caused by hypertension reached 210.3 billion yuan in 2013, accounting for $6.61 \%$ of the total health cost in China. The number of people with high BP in China will rise by a large margin according to the new guidelines, which poses more severe challenges to medical and health resources.

\section{LIMITATIONS}

Some limitations should be considered when interpreting our data. First of all, this survey used the average BP measured two times on the same day, which might have led to false-positive diagnoses, resulting in overestimation of the prevalence rate. Second, the BP was measured by nurses themselves rather than the staff trained unifiedly, but all nurses had received professional knowledge of BP measurement. In addition, a unified description of the measurement methods and matters of attention were carried out in the study, which could ensure the reliability of the measurement results. Third, the different BP measuring instruments used might have had some effect on the data, but the sphygmomanometer had been tested and corrected. The BP measurement in the survey was carried out according to international measurement and quality control regulations, which could guarantee the reliability of the measurement results. Furthermore, the small proportion of men and nurses over 55 years old in this study might have had some influence on the study results. Finally, the generalisability of our results might have been restricted because the participants being recruited were from only one province in China. Future studies should be carried out to recruit participants from other cities in China.

\section{Author affiliations}

${ }^{1}$ Nursing Department, Second Hospital of Hebei Medical University, Shijiazhuang, China

${ }^{2}$ Department of Cardiology, Second Hospital of Hebei Medical University, Shijiazhuang, China

${ }^{3}$ Nursing Department, Second Hospital of Baoding, Baoding, China

${ }^{4}$ Nursing Department, Tangshan Gongren Hospital, Tangshan, China

${ }^{5}$ Nursing Department, Handan Central Hospital, Handan, China

${ }^{6}$ Neurology Hospital, Cangzhou Central Hospital, Cangzhou, China

${ }^{7}$ Nursing Department, The Second Affiliated Hospital of Xingtai Medical College, Xingtai, China

${ }^{8}$ Nursing Department, The People's Hospital of Langfang City, Langfang, China ${ }^{9}$ Nursing Department, The First Hospital of Qinhuangdao, Qinhuangdao, China

${ }^{10}$ Nursing Department, The First Affiliated Hospital of Hebei North University,

Zhangjiakou, China

${ }^{11}$ Nursing Department, Harrison International Peace Hospital, Hengshui, China

${ }^{12}$ Nursing Department, Chengde Central Hospital, Chengde, China

${ }^{13}$ Nursing Department, Dingzhou Maternal and Child Health Care Hospital, Dingzhou, China

${ }^{14}$ Nursing Department, The First Hospital of Xinji, Xinji, China

Acknowledgements This project was supported by the Hebei provincial Science and Technology Department (162777166).

Contributors WC conceived the study. WC, BZ, YH and YZ designed the study, drafted the manuscript and critically revised the manuscript for important intellectual content. JL, XC, XY, AZ, RJ, RZ, AF, YW, MY, LT, SC, JC and MZ conducted the research and collected data. JL, DF and MX analysed the data; WC, BZ, JL, YH and DF wrote the this article. All authors gave the final approval of the version to be published and are accountable for all aspects of the work in ensuring that questions related to the accuracy or integrity of any part of the work are appropriately investigated and resolved. WC is the corresponding author and guarantor.

Funding The authors have not declared a specific grant for this research from any funding agency in the public, commercial or not-for-profit sectors.

Competing interests None declared.

Patient consent for publication Not required.

Ethics approval The study was reviewed and approved by the Research Ethics Committee of The Second Hospital of Hebei Medical University (no. 2016225). Consent was implied by completion of the questionnaire. All participants were voluntary and had the right to participate or refuse without any reason. To protect the privacy of respondents, electronic data were saved in a secured computer of the hospital with restricted access.

Provenance and peer review Not commissioned; externally peer reviewed. Data availability statement No data are available. 
Open access This is an open access article distributed in accordance with the Creative Commons Attribution Non Commercial (CC BY-NC 4.0) license, which permits others to distribute, remix, adapt, build upon this work non-commercially, and license their derivative works on different terms, provided the original work is properly cited, appropriate credit is given, any changes made indicated, and the use is non-commercial. See: http://creativecommons.org/licenses/by-nc/4.0/.

\section{REFERENCES}

1. Agnoletti D, Valbusa F, Labat C, et al. Evidence for a prognostic role of orthostatic hypertension on survival in a very old institutionalized population. Hypertension 2016;67:191-6.

2. Chen W, Gao R, Liu L, et al. China cardiovascular disease report 2015. Chinese Circulation Journal 2016;31:521-8.

3. Lewington $\mathrm{S}$, Lacey $\mathrm{B}$, Clarke $\mathrm{R}$, et al. The burden of hypertension and associated risk for cardiovascular mortality in China. JAMA Intern Med 2016;176:524-32.

4. Chen W, Gao R, Liu L, et al. China cardiovascular disease report 2017. Chinese Circulation Journal 2018;33:1-8.

5. Qi S-F, Zhang B, Wang $\mathrm{H}-\mathrm{J}$, et al. Prevalence of hypertension subtypes in 2011 and the trends from 1991 to 2011 among Chinese adults. J Epidemiol Community Health 2016;70:444-51.

6. Liang Y, Liu R, Du S, et al. Trends in incidence of hypertension in Chinese adults, 1991-2009: the China health and nutrition survey. Int J Cardiol 2014;175:96-101.

7. Whelton PK, Carey RM, Aronow WS, et al. 2017 ACC/AHA/AAPA/ ABC/ACPM/AGS/APhA/ASH/ASPC/NMA/PCNA Guideline for the Prevention, Detection, Evaluation, and Management of High Blood Pressure in Adults: Executive Summary: A Report of the American College of Cardiology/American Heart Association Task Force on Clinical Practice Guidelines.

8. Kario K. Global impact of 2017 American heart Association/American College of cardiology hypertension guidelines: a perspective from Japan. Circulation 2018:137:543-5.

9. Wander GS, Ram CVS, Gurpreet SW C. Global impact of 2017 American heart Association/American College of cardiology hypertension guidelines: a perspective from India. Circulation 2018;137:549-50.

10. Wang J-G, Liu L, Ls L. Global impact of 2017 American College of Cardiology/American heart association hypertension guidelines: a perspective from China. Circulation 2018;137:546-8.

11. Wang Z, Chen Z, Zhang L, et al. Status of hypertension in China: results from the China hypertension survey, 2012-2015. Circulation 2018;137:2344-56.

12. Khera R, Lu Y, Lu J, et al. Impact of 2017 ACC/AHA guidelines on prevalence of hypertension and eligibility for antihypertensive treatment in United States and China: nationally representative cross sectional study. BMJ 2018;362.

13. Li $D$, Zeng $X$, Huang $Y$, et al. Increased risk of hypertension in young adults in Southwest China: impact of the 2017 ACC/AHA high blood pressure guideline. Curr Hypertens Rep 2019;21:21.
14. Li D, Huang J, Tang L, et al. Characteristics of job stressors, fatigue and change of blood pressure, blood glucose and lipid among ICU NRISES. Nurs J Chin PLA 2012;29:1-4.

15. Lo S-H, Lin L-Y, Hwang J-S, et al. Working the night shift causes increased vascular stress and delayed recovery in young women. Chronobiol Int 2010;27:1454-68.

16. Guo J, Zhu Y-C, Chen Y-P, et al. The dynamics of hypertension prevalence, awareness, treatment, control and associated factors in Chinese adults: results from CHNS 1991-2011. J Hypertens 2015;33:1688-96.

17. Afridi $\mathrm{HI}$, Talpur FN, Kazi TG, et al. Assessment of toxic elements in the samples of different cigarettes and their effect on the essential elemental status in the biological samples of Irish hypertensive consumers. J Hum Hypertens 2015;29:309-15.

18. Sun J, Buys NJ, Hills AP. Dietary pattern and its association with the prevalence of obesity, hypertension and other cardiovascular risk factors among Chinese older adults. Int J Environ Res Public Health 2014; 11:3956-71.

19. Ahn S, Zhao H, Smith ML, et al. Bmi and lifestyle changes as correlates to changes in self-reported diagnosis of hypertension among older Chinese adults. J Am Soc Hypertens 2011;5:21-30.

20. Li S, Yu J, Zhang L, et al. Hypertension and cardiovascular risk evaluation of Chinese cardiovascular physicians. Chin J Cardiol 2011;39:254-8.

21. Liu M, Wang D, Hao Y, et al. Risk factors of hypertension in medical staff in a Three-A level hospital in Zhengzhou. Evaluation and analysis of drug-use in hospitals of China 2015;15:267-9.

22. Commission CHaFP. Report on nutrition and chronic diseases in China (2015). People's Medical Publishing House 2015:33-50.

23. Li Y, Yang L, Wang L, et al. Burden of hypertension in China: a nationally representative survey of 174,621 adults. Int $J$ Cardiol 2017;227:516-23.

24. Lu J, Lu Y, Wang X, et al. Prevalence, awareness, treatment, and control of hypertension in China: data from 1.7 million adults in a population-based screening study (China peace million persons project). The Lancet 2017;390:2549-58.

25. Lee JH, Kim S-H, Kang S-H, et al. Blood pressure control and cardiovascular outcomes: real-world implications of the 2017 ACC/ AHA hypertension guideline. Sci Rep 2018;8:13155.

26. Watkins DA. Implications of the 2017 ACC/AHA hypertension guideline for public health in Nepal. JAMA Netw Open 2018;1:e180778.

27. Lemstra M, Alsabbagh MW. Proportion and risk indicators of nonadherence to antihypertensive therapy: a meta-analysis. Patient Prefer Adherence 2014;8:211-8.

28. Wang W, Lau Y, Loo A, et al. Medication adherence and its associated factors among Chinese community-dwelling older adults with hypertension. Heart Lung 2014;43:278-83.

29. Law MR, Morris JK, Wald NJ. Use of blood pressure lowering drugs in the prevention of cardiovascular disease: meta-analysis of 147 randomised trials in the context of expectations from prospective epidemiological studies. BMJ 2009;338:b1665. 